\title{
The Experiential Analysis of Woven Fabric for Reproduction
}

\author{
Shariful Islam1, Sutapa Chowdhury², Shilpi Akter ${ }^{1}$ \\ ${ }^{1}$ Department of Fabric Engineering, Bangladesh University of Textiles, Dhaka, Bangladesh \\ ${ }^{2}$ Department of Textile Fashion and Design, Bangladesh University of Textiles, Dhaka, Bangladesh \\ Email: Sharifultextiles@gmail.com, sutapa.shairy@yahoo.com, shilpiakt@gmail.com
}

How to cite this paper: Islam, S., Chowdhury, S. and Akter, S. (2018) The Experiential Analysis of Woven Fabric for Reproduction. Journal of Textile Science and Technology, 4, 18-48.

https://doi.org/10.4236/jtst.2018.41002

Received: May 21, 2017

Accepted: February 25, 2018

Published: February 28, 2018

Copyright $\odot 2018$ by authors and Scientific Research Publishing Inc. This work is licensed under the Creative Commons Attribution International License (CC BY 4.0).

http://creativecommons.org/licenses/by/4.0/

cc) (i) Open Access

\begin{abstract}
The aim of this article was to express the importance of this projected work in the field of present competitive textile-world as fabric manufacturing industries are competing with each other to be unique and aristocrat with their products for attaining customer's attention and increasing their significance to others. To be superior in market, research is the first priority in this perspective competing field. Industries are producing a wide variety of products with some very good comfort properties in fabrics. Due to achieving this, different properties like construction, weave, internal structure, use of variety of yarn, inner-structural changes are brought in fabrics. The more an industry is advanced with its products, the more it will get market value which is very important. Market research in this field is fundamental prior to going for production. An experimental study may be applied in the market on various products with a view to attaining a good annual turnover with production and manufactures. All these parameters like development, growth, market values etc. are strongly dependent on the analytical and research activities of a group. Considering all, analysis on a fabric and its properties is very much fundament and important.
\end{abstract}

\section{Keywords}

Fabric Analysis, Dyes Identification, Yarn Analysis

\section{Introduction}

There is a great importance of this project for doing investigational analysis of a woven fabric for reproduction that is expressed all over this project. This project is a practical based project which was performed in a vertical integrated composite mill as this project has a huge potentiality that needs huge setup to perform 
all the activities and test required to complete this whole project effectively. This article can be helpful to the personnel newly engaged in textile field or in any research organization where investigation, analysis and development happen. Swatch is a small piece of fabric that is given by the buyer to the fabric manufacturer to construct another new fabric, where all the genuine and accurate characteristics will be appeared after the fabric is produced. Experimental analysis can be expressed as a step by step examination on fabric sample, which is associated with the advancement of scrutinizing something pioneering that provides fresh thoughts as per any requirement by means of gradual attempt. In another term, analysis is the systematic study on a particular substance for duplicating something new. The courses of actions those are applied by the engineers during swatch analysis are stated in this topic.

\section{Reasons of swatch analysis}

- To reproduce new fabric according to buyer's swatch.

- To do costing by knowing the details of the fabric.

\section{Swatch Analysis}

\subsection{Identification of Type of Fabric}

Fabric is a flexible product/material that is constructed from fibers, filaments or yarns by following some processes like weaving, knitting, intertwining or directly from webs of fibers through chemical bonding, thermal/ mechanical process etc. Fabric type is identified, on the basis to be produced, like woven, knit or non-woven etc. As we will analyze and produce woven fabric, so after identifying we will work with woven fabric only.

Woven: Fabric is made by the interlacement at right angle in between two sets of yarns those are warp and weft. The warp yarns remain longitudinally as per length of the fabric and the weft yarns remains transversely through the fabric.

Knit: Knit fabric is made by interloping of one set of yarn. It involves of making yarns into loops, every one of it is typically released after a subsequent loop is designed.

Non-woven: Fabrics are made by chemical, thermal, mechanical process or by adhesive gummy bonded material. Nonwoven fabrics are soft, warm, flexible, bendable, permeable and porous products, consisting of one or more fiber layers.

Intertwining and twisting: These fabrics are made by braiding, plaiting, knotting, linking of fibers or by twisting of fibers/yarns into fabrics, where yarns are caused to intertwine with each other at right angles or some other angles.

\subsection{Identification of Coloration of Fabric}

Dyeing or printing is the procedure of decoration or coloration of a white fabric, by means of different types of dye particles. This term refers to how the fabric is colored. Yarn dyed, solid dyed and printed fabrics can be identified by different 
ways.

Yarn dyed fabric: Yarn dyeing is the procedure where, yarns of warp and weft yarns are dyed separately, in cone or package form, to make stripe and check effect in fabric during weaving. Yarn dyed fabrics are the fabrics where, every yarns are dyed individually before weaving to create some special colored effect or check and stripe effect in fabric.

Solid dyed fabric: Solid dyeing is the procedure where, the full fabric is dyed at a time in continuous rope form or batch form, to create only a single colored appearance in fabric (not check or stripe effect) after the fabric has been made. Check and colored effects are not created by solid dyeing procedure, but create same solid color effect in the both sides of fabric.

Printed fabric: Printing is the procedure of applying color/dye particles to a localized area that is confined to a small area of fabric according to print design, repeat, pattern and color with the help of print paste or others [1]. The main difference between dyeing (solid dyeing) and printing is that, dyeing is the uniform and appropriate application of only one color on the whole fabric (full fabric is colored/dyed by single color), on the other hand, printing is the use of one or more colors/dye particles to the limited/certain/definite area in a fabric as per print design, pattern, repeat and color.

\subsection{Identification of Warp and Weft Direction in the Fabric}

As a woven fabric has two directions namely warp and weft, where warp runs vertically along the fabric and weft runs horizontally. This analysis is also fundamental for a fabric to reproduce [2]. Figure 1 shows the direction of warp and weft.

\section{Identification of Warp in the Fabric:}

- The selvedge direction shows the warp direction.

- Density of yarn is more in warp direction than that of weft.

- Warp yarn may be finer than weft yarn.

- Crimp will be less in warp direction due to tension from loom

- Length direction is warp direction.

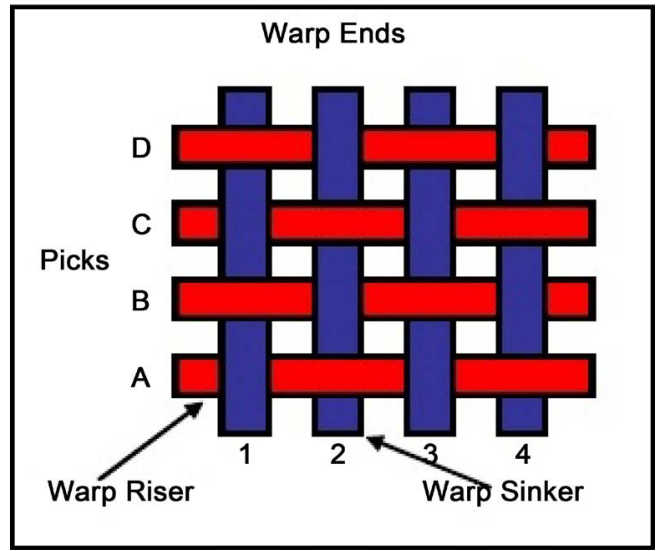

Figure 1. Warp and weft identification. 
- Lower elongation is found in warp direction.

- Because of loom tension, warp yarns are more parallel and straighter.

- Warp yarns have higher twist than weft yarn.

- If a yarn holds any sizing element, then the sized yarn is basically warp yarn.

- Generally, stripe effect is done in warp way. Identification of Weft in Fabric:

- Width wise direction is weft direction.

- The yarn from selvedge to selvedge is weft yarn.

- Density of weft yarn will be less than warp yarn in fabric.

- Weft yarn may be coarser than warp yarn.

- Crimp will be more in weft direction.

- Higher elongation is found in weft direction.

- Weft yarns have lower twist.

- Fancy or decorative yarns are mainly used in weft direction.

\subsection{Identification of Face Side and Back Side of Fabric}

- In case of brushed or peach fabric, most often the face side is peached or brushed (back side may also be with peach effect, but most often face side is peach side).

- Smoothness and clearness of face side of a fabric will be more than the backside.

- Twill lines will be more visible in face side of the fabric.

- In some cases, special chemicals are being used in the face side of the fabric that is why the face side of the fabric seems too distinctive.

- Fancy designs have smoother weaves on the face side where back-side of this design becomes loose.

- Cords effects are more visible in face side of the fabrics.

- Sateen fabrics show face by weft on top and satin warp on top.

- Dobby fabrics have more weave prominence effect in face side.

\subsection{Nature of Fabric}

According to the number of warp beam (number of layer) two types of fabrics are available namely single cloth and double cloth.

Single cloth: Interlacement in between warp ends and weft picks of one layer of threads from only a single warp beam that produces single cloth. Single cloths are easy to produce and production cost is not so high.

Double cloth: Two layers of thread from two warp beams produce double cloth, which is woven one on top of another and subsequently stitched together. Another name of double cloth fabric is two-ply fabric. Minimum two series of warp and weft threads are required for producing two-ply fabric. Interlacement in between face warp yarns with face weft yarns creates upper layer, and interlacement in between back warp yarns with back weft yarns makes lower layer [3]. 


\subsection{Identifying Shedding Mechanisms Used in the Swatch on the Basis of Weave}

Plain weave fabric: Crank-shedding mechanism is used only for producing plain-woven fabric by high-speed loom like air jet or water jet. Plain-weave fabric can also be produced by cam shedding mechanism and dobby shedding mechanism.

Twill weave fabric: Twill-weave fabric can be produced by cam shedding mechanism. It can control the lifting or lowering of heald frames for keeping up a correspondence to the lifting diagram. If the weave design of fabric is changed, the cams should be rearranged. Twill weave fabric can also be produced by dobby shedding mechanism.

Combination of plain and twill in a same fabric (in a weave repeat): Only plain weave, only twill weave or the combination of both plain and twill weave (plain + twill in a repeat) fabric is also possible to produce by dobby shedding mechanism. It can produce a fabric where the combination of plain weave and twill weave will be seen in a repeat of weave [4].

Image and very critical/crucial design on fabric: Jacquard shedding mechanism is the most critical, crucial and complex shedding mechanism where, every warp ends can be controlled individually with the help of harness cords. Image, photo, sticker, human, bird, flower design or any other critical designs are produced by jacquard shedding mechanism.

\subsection{Identify Twill Direction of Twill Weave Fabric}

In regular twill weave fabric, diagonal twill lines are created in fabric surface towards left hand or right hand direction.

$\mathrm{Z}$ or RHT Twill: If diagonal twill line goes to upper right hand direction, from the lower left hand direction that is called right handed twill or $\mathrm{Z}$ twill. It is formed by upward movement of the interlacing points, if the initial point is bottom left corner.

S or LHT Twill: If diagonal twill line goes to upper left hand direction, from the lower right hand direction that is called left-handed twill or S twill. It is produced by downward movement of the interlacing points, if the initial point is bottom left corner.

\subsection{Identify Twill Angle of Twill Weave Fabric}

In face side of a fabric, twill angle is called the angle in among the diagonal twill line and a fantasy horizontal line or axis parallel to the weft picks. Twill angle is measured by following formula, Equation (1)

$$
\operatorname{Tan} \theta=\left(\frac{\text { Rate of advancement of twillupward }}{\text { Rate of advancement of twill downward }}\right) \times\left(\frac{\text { EPI }}{\text { PPI }}\right)
$$

Equation (1): Basic formula for Identifying twill angle of twill weave fabric

Exact $45^{\circ}$ Twill angle: If the EPI and PPI of a fabric is equal to each other, and warp over weft or weft over warp interlacement is equal, then the twill angle 
will be exactly $45^{\circ}$. Equation (2) is used to find out the twill angle of exact $45^{\circ}$.

Find out twill angle from the below construction

$$
\left(\mathrm{Ne}_{\mathrm{wp}} \times \mathrm{Ne}_{\mathrm{wf}} / \mathrm{EPI} \times \mathrm{PPI}\right)
$$

$40 \times 40 / 100 \times 100$, weave $2 / 2$.

$$
\operatorname{Tan} \theta=\left(\frac{2}{2} \times \frac{100}{100}\right)
$$

Equation (2): Identify twill angle of twill weave fabric

So, $\operatorname{Tan} \theta=1 \times 1$

$$
\theta=45^{\circ}
$$

Hence, Twill angle is $45^{\circ}$.

Greater than $45^{\circ}$ twill angle: If EPI is more than PPI in fabric, and warp over weft is more, weft over warp is less, then the twill angle will be more than $45^{\circ}$, that is high angle or steep twill. Equation 3 is used to find out the twill angle of greater than $45^{\circ}$.

Find out twill angle from the below construction

$$
\left(\mathrm{Ne}_{\mathrm{wp}} \times \mathrm{Ne}_{\mathrm{wf}} / \mathrm{EPI} \times \mathrm{PPI}\right)
$$

$40 \times 30 / 100 \times 80$, weave $3 / 1$.

$$
\operatorname{Tan} \theta=\left(\frac{3}{1} \times \frac{100}{80}\right)
$$

Equation (3): Identify twill angle of twill weave fabric

$$
\begin{gathered}
\operatorname{Tan} \theta=3 \times 1.25=3.75 \\
\operatorname{Tan} \theta=3.75 \\
\theta=75^{\circ}
\end{gathered}
$$

Hence, Twill angle is $75^{\circ}$.

Less than $45^{\circ}$ twill angle: If EPI is less than PPI in fabric, warp over weft is less, weft over warp is more, then the twill angle will be less than $45^{\circ}$, which is low angle or flat twill. Equation (4) is used to find out the twill angle of less than $45^{\circ}$.

Find out twill angle from the below construction

$$
\left(\mathrm{Ne}_{\mathrm{wp}} \times \mathrm{Ne}_{\mathrm{wf}} / \mathrm{EPI} \times \mathrm{PPI}\right)
$$

$20 \times 30 / 70 \times 90$, weave $2 / 5$.

$$
\operatorname{Tan} \theta=\left(\frac{2}{5} \times \frac{70}{90}\right)
$$

Equation (4): Identify twill angle of twill weave fabric

$$
\begin{gathered}
\operatorname{Tan} \theta=0.4 \times 0.7778=0.311 \\
\operatorname{Tan} \theta=0.311 \\
\theta=17.28^{\circ}
\end{gathered}
$$

Hence, Twill angle is $17.28^{\circ}$. 


\subsection{Identifying Repeat Size}

The term "Repeat size" adjusts two things in a fabric. One thing is repeat of weave pattern and another one is repeat of pattern color.

A. Repeat of Weave pattern: Weave repeat is the minimum amount of yarns those are contained in only a one full weave. Weave repetition is a numerical expression of any given weave that designates the least number of warp and weft yarns for an agreed weave structure. It is the amount of total number of yarns in a repeat of weave structure [5].

Some examples are given below for the repeat of weave structure-

For plain weave (in a repeat of $\frac{1}{1}$ weave)

Warp: Two yarns will be available in warp direction.

Weft: Two yarns will be available in weft direction.

For twill weave (in a repeat of $\frac{2}{2}$ weave)

Warp: Four yarns will be available in warp direction.

Weft: Four yarns will be available in weft direction.

For twill weave (in a repeat of $\frac{2}{1}$ weave)

Warp: Three yarns will be available in warp direction.

Weft: Three yarns will be available in weft direction.

B. Repeat of color: In case of yarn dyed stripe or check fabric, Pattern color repeat is the minimum amount of length that contains only a one full pattern both in warp and weft direction individually. Pattern color repeat will be identified by measuring the repeat area in linear scale. If color pattern is mentioned like 8 " $\times 8$ " means, 8 " repeat in warp direction and 8 " repeat in weft direction.

\subsection{Analyzing the Type of Weave Structure Used in Swatch}

It indicates the types of woven structure; whether it is simple weave structure or compound weave structure.

- Simple structure: In simple weave structure, there is only a series of warp ends and one series of weft picks are available which interlace each other in a perpendicular way. All the adjacent warp ends and weft picks are parallel to each other those play a significant responsibility in determining the properties of the fabric.

- Compound structure: In compound weave structure, there may remain more than one series of warp ends and weft picks. From them, one series interlace each other to form the base fabric and the other series forms the ornamentation. Here the adjacent yarns may not remain parallel to each other [6].

\subsection{Identifying Weave Structure Used in Swatch}

Weave specifies the interlacement in between warp ends and weft picks at right angle in fabric. During interlacement, if warp ends are lifted above weft picks 
that is called warp overlap and if warp ends are lowered below weft picks that is called weft overlap. In the design diagram of weave structure, the longitudinal direction of the square indicates the warp ends and the transverse direction indicates the weft picks. Mainly there are three types of weaves are available namely plain, twill and satin.

\subsection{Identifying Drafting/Drawing Plan to Be Required in Swatch}

Drafting or drawing plan specifies the method of insertion of the warp ends through the heal eye of the heal frame and also represents the number of heal shaft would be required for a given weave repeat. There are many types of drafts are available like Straight draft, pointed draft, Skip and sateen draft, broken draft, Divided draft, Grouped draft, Curved draft, and Combination draft. Amongst them, straight draft is the most commonly used draft and the simplest of all types of drafting plans which is discussed in this book. In drafting/drawing plan, the space between two vertical lines and horizontal lines correspondingly indicates warp yarns and heald shafts.

\subsection{Identifying Lifting Plan to Be Required in Swatch}

Lifting plan expresses the order of lifting or lowering of heal shafts or heal frames in every successive insertion of picks. In this plan, the vertical spaces specify the heal shafts and the horizontal spaces designate the weft picks. Lifting plan depends upon drafting plan that would be used. For straight draft, lifting plan most often remains as same as weave design. Figure 2 describes weave structure, drawing/drafting and lifting plan.

An example is given below for mentioning weave design along with drafting plan and lifting plan.

\subsection{Identifying Denting Plan to Be Required in Swatch}

According to denting plan, every warp ends will be inserted throughout the dent

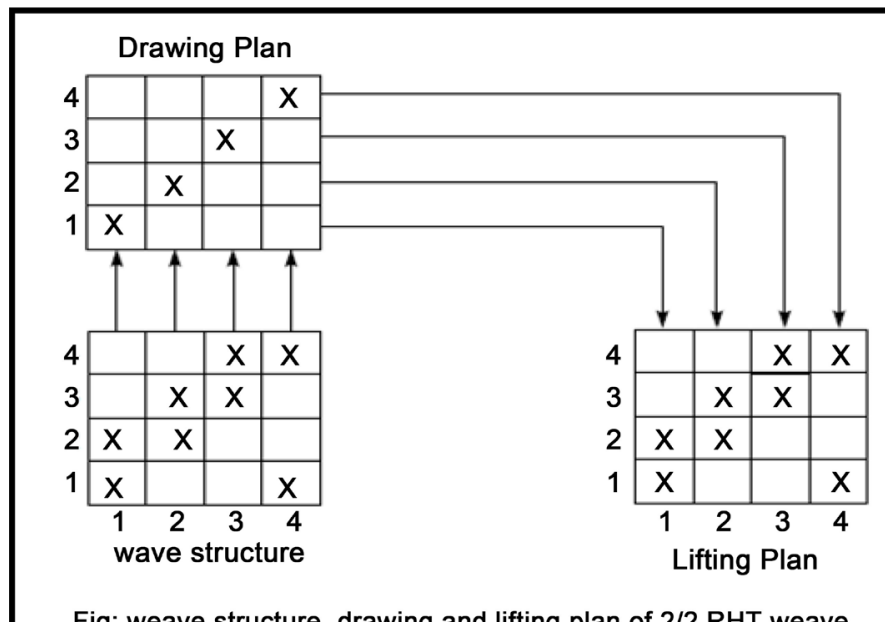

Fig: weave structure, drawing and lifting plan of 2/2 RHT weave

Figure 2. Weave structure, drawing/drafting and lifting plan. 


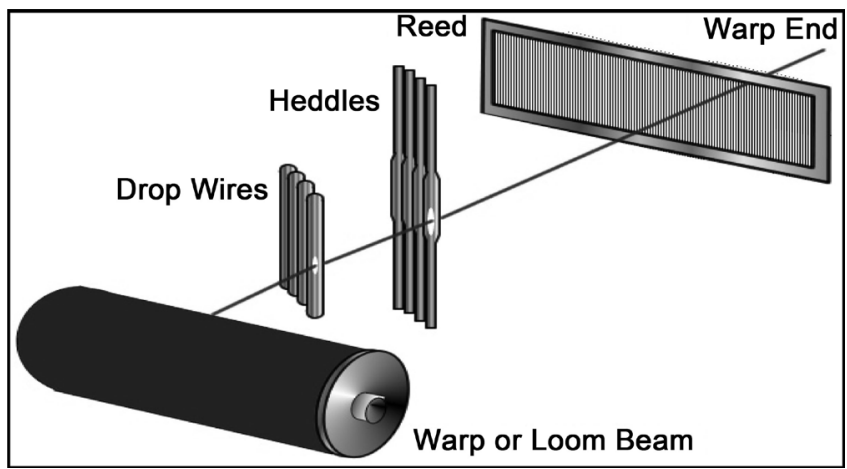

Figure 3. Warp passage through reed and drop wire.

of reed. One, Two, three or four warp ends can be inserted per each dent as required. There are some fabrics, which require an unbalanced order of denting to highlight certain design feature, and their arrangement of ends in dent of reed, becomes a part of design, that must be pointed out cautiously, in the accurate way, in respect to the weave design, drafting and lifting plan. An example of a denting plan is given below for matt or basket weave design. Figure 3 describes the passage of warp yarn through reed and drop wire.

\subsection{Identifying Warp Yarn's Count from Swatch}

Yarn count is a mathematical representation that describes the fineness, coarseness, thickness or thinness of yarns. Actually, yarn count is a number that indicates the mass per unit length or the length per unit mass of yarns. During swatch analysis, to identify the count of yarns from buyer's supplied swatch, is an important issue. Warp yarns count can be measured by the below mentioned formula. Equation (5) describes the measurement of warp yarn count.

$$
\text { Warp Count }(\mathrm{Ne})=\frac{(\text { No. of warp yarns } \times \text { length in } \mathrm{cm} \times 0.0059)}{\text { warp yarn's weight in } \mathrm{gm}}
$$

Equation (5): Identifying warp yarn's count

The procedure: Take some amount of warp yarns from the fabric having same length $(\mathrm{cm})$, then multiply the value with a constant $(0.0059)$ and then divided the result by the weight of warp yarns. Constant $0.0059=$ If 1 yarn has 1 $\mathrm{cm}$ of length, $1 \mathrm{Ne}$ of count then that yarn's weight will be $0.0059 \mathrm{gm}$.

Suppose, from a sample, 30 warp yarns are taken of each having $25 \mathrm{~cm}$ in length. Then multiply these values with constant (0.0059) and then divide the result by the weight $(0.1471 \mathrm{gm})$ of that 30 warp yarns. So warp yarns count is 30 Ne.

$$
\begin{gathered}
\text { Warp Count }(\mathrm{Ne})=\frac{(\text { No. of warp yarns } \times \text { length in } \mathrm{cm} \times 0.0059)}{\text { warp yarn's weight in gm }} \\
\text { Warp Count }(\mathrm{Ne})=\frac{(30 \times 25 \mathrm{~cm} \times 0.0059)}{0.1471 \mathrm{gm}} \\
\text { Warp Count }(\mathrm{Ne})=30.08 \mathrm{Ne}
\end{gathered}
$$




$$
\text { Warp Count }(\mathrm{Ne})=30 \mathrm{Ne} \text { (approximately) }
$$

The count $(\mathrm{Ne})$ for the supplied swatch is $30 \mathrm{Ne}$.

\subsection{Identifying Weft Yarn's Count from Swatch}

Yarn count is a numerical expression that defines the fineness, coarseness, thickness or thinness of yarns. Actually, yarn count is a number that indicates the mass per unit length or the length per unit mass of yarns. During swatch analysis, to identify the count of yarns from buyer's supplied swatch, is an important issue. Weft yarns count can be measured by the below mentioned formula. Equation (6) describes the measurement of weft yarn count.

$$
\text { Weft Count }(\mathrm{Ne})=\frac{(\text { No. of weft yarns } \times \text { length in } \mathrm{cm} \times 0.0059)}{\text { weft yarn's weight in } \mathrm{gm}}
$$

Equation (6): Identifying weft yarn's count

The procedure: Take some amount of weft yarns from the fabric having same length $(\mathrm{cm})$, then multiply the value with a constant $(0.0059)$ and then divided the result by the weight of weft yarns. Constant $0.0059=$ If 1 yarn has $1 \mathrm{~cm}$ of length, $1 \mathrm{Ne}$ of count then that yarn's weight will be $0.0059 \mathrm{gm}$.

Suppose, from a sample, 30 weft yarns are taken of each having $25 \mathrm{~cm}$ in length. Then multiply these values with constant (0.0059) and then divide the result by the weight $(0.221)$ of that 30 weft yarns. So weft yarns count is $30 \mathrm{Ne}$.

$$
\begin{gathered}
\text { Weft Count }(\mathrm{Ne})=\frac{(\text { No. of weft yarns } \times \text { length in } \mathrm{cm} \times 0.0059)}{\text { weft yarn's weight in } \mathrm{gm}} \\
\text { Weft Count }(\mathrm{Ne})=\frac{(30 \times 25 \mathrm{~cm} \times 0.0059)}{0.2210 \mathrm{gm}} \\
\text { Weft Count }(\mathrm{Ne})=20.02 \mathrm{Ne} \\
\text { Weft Count }(\mathrm{Ne})=20 \mathrm{Ne} \text { (approximately) }
\end{gathered}
$$

The count $(\mathrm{Ne})$ for the supplied swatch is $20 \mathrm{Ne}$.

\subsection{Identifying Thread Count in the Swatch}

Thread count is the measurement of total number of threads or yarns in both warp and weft direction, inside a one inch square of fabric. Thread count is affected by some factors like thickness of yarns, ply of yarns etc. Use of finer yarns and single ply yarns allow to fit more yarns in the square inch. Finer yarns make the fabric smoother that contains higher thread count, which results in compact fabric. Alternately, coarser yarns make the fabric rough that contains lower thread count. Mainly lower thread count with finer yarns make the fabric loose. Thread count is measured by counting glass. Counting glass is a useable oneinch square shaped substance that is made by magnifying glass, to count or measure the total number of yarns in both warp and weft direction in an inch of fabric. Figure 4 describes thread count by the use of a counting glass. 


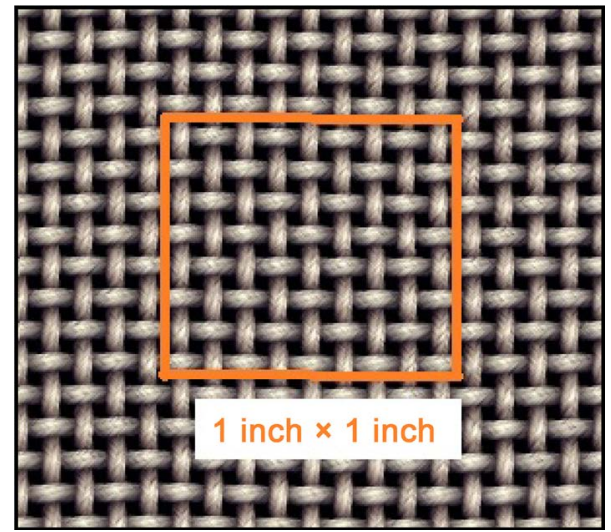

Figure 4. Thread counting through a counting glass.

\subsection{Identifying Ends per Inch (EPI)/Picks per Inch (PPI) Measurement}

Ends per inch or Picks per inch is the number of yarns, per inch length of woven fabric that means how many yarns are contained in an inch of fabric. Basically, higher threads per inch creates compact, dense and finer fabric. EPI/ PPI varies in fabric on the basis of thickness/thinness of yarns. Finer yarns contain more EPI or PPI compared to coarser yarns. EPI and PPI is increased after weaving the fabric and it is increased again after being washed. EPI and PPI are measured by Counting Glass. Normally EPI is more than PPI in fabric.

\subsection{Identifying Fabric Construction of the Woven Swatch}

The Construction of a fabric refers the count of yarn both in warp and weft direction of fabric, and also the measurement of ends per inch and picks per inch area with width. Actual Construction is $=($ Warp count $\times$ weft count $/ E P I \times P P I) \times$ width ".

Suppose, there is a fabric whose warp and weft yarn count is respectively 30 $\mathrm{Ne}$ and $20 \mathrm{Ne}$. ends per inch measurement is 80 and picks per inch measurement is 60 . Fabric width is 59 ". So actual construction will be: $(30 \times 20 / 80 \times 60) \times 59$ ".

Oxford has a conjugal/pair parallel yarn in warp direction. Construction: $(30+30) \times 20 / 80 \times 60$.

Ottoman has a conjugal/pair parallel yarn in weft direction. Construction: $30 \times(20+20) / 80 \times 60$.

Basket has a conjugal/pair parallel yarn in both warp and weft direction. So, basket weave construction will be: $(30+30) \times(20+20) / 80 \times 60$.

If warp yarns are double or two plied, then it will be expressed like: $30_{2} \times 20 / 80 \times 60$.

If weft yarns are double or two plied, then it will be expressed like: $30 \times 20_{2} / 80 \times 60$.

Spandex is not used alone in fabric. It is used by wrapping with another fiber. If Spandex of 70 Denier is combined with another fiber in weft way, then construction: $30 \times(20+70 \mathrm{D}) / 80 \times 60$.

$(30+30 \mathrm{SB}) \times(20+20 \mathrm{SB}) / 80 \times 60$ means, one $30 \mathrm{Ne}$ non-slub and another 30 
Ne slub yarn comes alternately, and one $20 \mathrm{Ne}$ non-slub and another $20 \mathrm{Ne}$ slub yarn comes alternately.

\subsection{Identifying Fabric Cover Factor of the Fabric}

It designates the degree to which the part of a fabric is enclosed with yarns. A woven fabric has two cover factors, one is warp and another is weft cover factor. Alternatively, cover factor is the ratio of the area covered by the yarn to the whole area of the fabric. Yarn diameter and hairiness have a direct effect on fabric cover factor. It expresses the compactness, firmness, solidity and density of fabric. Equation (7) describes cover factor of total fabric. Equation (8) and equation (9) describes warp and weft cover factor.

$$
\text { Fabric Cover Factor }=\left(K_{1}+K_{2}\right)-\left\{\frac{K_{1} \times K_{2}}{28}\right\}
$$

Equation (7): Identifying fabric cover factor.

Here,

$$
\begin{gathered}
\text { Warp cover factor } K_{1}=\left(\frac{\text { EPI }}{\sqrt{\text { Warp count }}}\right) \\
\text { Equation (8): Warp cover factor. } \\
\text { Weft cover factor } K_{2}=\left(\frac{\text { PPI }}{\sqrt{\text { Weft count }}}\right) \\
\text { Equation (9): Weft cover factor. }
\end{gathered}
$$

\subsection{Identifying Fabric Thickness of the Swatch}

Fabric thickness is defined as the upright/perpendicular distance of depth, throughout the fabric, which determines the difference of dimension in between the upper surface and lower surface of fabric. Fabric thickness depends on fabric weave, EPI, PPI, yarn count that means the thickness or thinness of yarn, yarn diameter, yarn twist etc. Fabric thickness gauge is used to measure the distance in between the upper surface and lower surface of fabric. Fabric thickness should be measured at least at three different positions in fabric and then take the average reading in millimeter scale.

Fabric thickness = distance between upper surface and lower surface of fabric by machine.

\subsection{Identifying the Physical Weight (GSM) of Swatch}

The full meaning of GSM stands for fabric's weight in "Gram per Square Meter" that is very important to know the weight of a fabric during analysis, before manufacturing the fabric and after getting the finished fabric to full fill buyer's requirements. GSM is the method of taking the weight of a fabric in grams, measure the length in meter (1) and width in meter (1). GSM can be measured physically by following some easy ways that includes GSM round cutting, square cutting etc. 
Process 01: Measurement of GSM of fabric by GSM cutter: To measure the weight of a fabric in gram per square meter, is considered as physical test of fabric that requires a GSM cutter of round shape. The diameter of the cutting section of GSM cutter is $11.28 \mathrm{~cm}$ and radius is $5.64 \mathrm{~cm}$. Actually, GSM round cutter is a reduced shape (1/100) that's why the weight of a sample fabric is taken in grams and multiply with 100 . At first, cut the fabric with GSM cutter on a rubber pad then take weight of the fabric by an electric balance and multiplied the value with 100. The value will show in "gram per square meter" of that exacting fabric. GSM cutter is circular that cuts $1 / 100$ of a square meter of a fabric area.

Assume, weight of a fabric is $2.80 \mathrm{gm}$ in electric balance. Multiplying with 100 it would be $280 \mathrm{gm}$. To convert the weight in oz/ $/ \mathrm{yd}^{2}$ from $\mathrm{gm} / \mathrm{m}^{2}$, divide the gram by 33.906 which will express the weight in $\mathrm{oz} / \mathrm{yd}^{2}$. So $280 \mathrm{gm} / \mathrm{m}^{2}$ is $8.2581 \mathrm{oz} / \mathrm{yd}^{2}$.

Process 02: Square cutting process: We can also take the weight of a fabric without GSM cutter. If we cut a fabric by $10 \mathrm{~cm}$ in warp direction and $10 \mathrm{~cm}$ in weft direction like a square $(10 \mathrm{~cm} \times 10 \mathrm{~cm})$ then take the weight by electric balance machine and then multiply with 100 , we will also get the GSM $\left(\mathrm{gm} / \mathrm{m}^{2}\right)$ a fabric. To convert the weight in $\mathrm{oz} / \mathrm{yd}^{2}$ from $\mathrm{gm} / \mathrm{m}^{2}$, divide the gram by 33.906 which will express the weight in $\mathrm{oz} / \mathrm{yd}^{2}$.

We can also take GSM, by weighting from the square cutting of $(100 \mathrm{~cm} \times 100$ $\mathrm{cm}$ fabric), $(50 \mathrm{~cm} \times 50 \mathrm{~cm}$ fabric multiply with 4$)$, and $(25 \mathrm{~cm} \times 25 \mathrm{~cm}$ fabric multiply with 16).

\subsection{Identifying the Calculated Weight (GSM) from Fabric Construction}

Weight (GSM) of a buyer's supplied swatch can be measured by calculation from the construction of fabric. Equation (10) describes GSM from construction.

$$
\mathrm{GSM}=\left[\left\{\frac{\mathrm{EPI} \times 1.03}{\text { Ne warp }}\right\}+\left\{\frac{\mathrm{PPI} \times 1.05}{\text { Ne weft }}\right\}\right] \times 23.25
$$

Equation (10): Identifying the calculated weight (GSM) from fabric

This value will be expressed in gram per square meter $\left(\mathrm{gm} / \mathrm{m}^{2}\right)$. If we want to convert this value into ounce per square yard $\left(\mathrm{oz} / \mathrm{yd}^{2}\right)$ then divide the GSM value by 33.906 to get $\mathrm{oz} / \mathrm{yd}^{2}$. Again if we multiply 33.906 with oz/yd $\mathrm{d}^{2}$ then we will get the value in $\mathrm{GSM}\left(\mathrm{gm} / \mathrm{m}^{2}\right)$.

Where $1.03\{(3 \%),(1+$ warp crimp $)\}$ and $1.05\{(5 \%),(1+$ weft crimp $)\}$ are crimp percentage. Crimp is a changeable value from fabric to fabric. After measuring the warp and weft crimp, we can calculate the exact weight.

\subsection{Identifying the Difference\% between Physical \& Calculated Weight}

It is another important thing that is also required for proofing the analysis of weight with physical and calculated weight. The fewer the value of difference\% is, the more accurate the weight analysis is. Equation (11) describes the differences in between physical and calculated weight. 
Let, the physical and the calculated weight of a swatch is correspondingly 5.05 $\mathrm{oz} / \mathrm{yd}^{2}$ and $4.98 \mathrm{oz} / \mathrm{yd}^{2}$. Find out the difference $\%$ between physical \& calculated weight?

$$
\text { Difference } \%=\left\{\frac{(\text { Physical weight }- \text { Calculated weight })}{\text { Physical Weight }}\right\} \times 100
$$

Equation (11): Identifying the Difference\% between physical \& calculated weight

$$
\begin{gathered}
\text { Difference } \%=\left\{\frac{\left(5.05 \mathrm{oz} / \mathrm{yd}^{2}-4.98 \mathrm{oz} / \mathrm{yd}^{2}\right)}{5.05 \mathrm{oz} / \mathrm{yd}^{2}}\right\} \times 100 \\
\text { Difference } \%=0.0138 \times 100=1.38 \%
\end{gathered}
$$

The tolerance level is $\pm 5 \%$ on physical weight.

\subsection{Identifying the Calculated Spandex Content Percentage in Fabric}

Calculate the amount of spandex percentage in a core yarn by the below mentioned formula-

Calculation of Spandex\% from the yarn of fabric construction: $\{40 \times(40+40 \mathrm{D}) / 128 \times 70\} \times 54$.

Warp and weft yarn count is $40 \mathrm{Ne}$, Spandex count is 40 denier, EPI and PPI are 128 and 70. Equation (12) describes the spandex\% in yarn. Equation (13) describes warp yarn crimp. Equation (14) describes weft yarn crimp. Equation (15) describes warp yarn weight. Equation (16) describes calculated weft yarn weight. Equation (17) describes spandex\% in fabric.

Solution:

Weft yarn count is $40 \mathrm{Ne}=\frac{5315}{40}=132.875$ Denier.

$$
\text { Spandex percentage in yarn }=\left(\frac{40 \mathrm{D}}{132.875}\right) \times 100
$$

Equation (12): spandex percantage in yarn

Percentage in yarn $=30.10 \%$

If draft is 4 , then Spandex in yarn $=\frac{30.10 \%}{4}=7.526 \%$.

$$
\text { Warp yarn crimp }=\frac{\text { (yarn's stretched length }- \text { yarn's length in fabric) }}{\text { yarn's length in fabric }}
$$

Equation (13): warp yarn crimp

$$
\begin{aligned}
& \text { Warp yarn crimp }= \frac{(19-18)}{18}=0.05556 \\
& \text { Weft yarn crimp }= \frac{(\text { yarn's stretched length }- \text { yarn's length in fabric })}{\text { yarn's length in fabric }} \\
& \text { Equation (14): weft yarn crimp }
\end{aligned}
$$

Weft yarn crimp $=\frac{21.5-18}{18}=0.1944$ 
Calculated warp yarn weight $=\left\{\left(\frac{\text { EPI }}{\text { warp count Ne }}\right) \times(1+\right.$ warp crimp $\left.)\right\} \times \frac{16 \times 36}{840}$

Equation (15): Calculated warp yarn weight

Calculated warp yarn weight $=\left\{\left(\frac{128}{40}\right) \times(1+0.05556)\right\} \times 0.6857$

Calculated warp yarn weight $=(3.2 \times 1.05556) \times 0.6857$

Calculated warp yarn weight $=2.3161$

Calculated weft yarn weight $=\left\{\left(\frac{\text { PPI }}{\text { weft count Ne }}\right) \times(1+\right.$ weft crimp $\left.)\right\} \times \frac{16 \times 36}{840}$

Equation (16): Calculated weft yarn weight

Calculated weft yarn weight $=\left\{\left(\frac{70}{40}\right) \times(1+0.1944)\right\} \times 0.6857$

Calculated weft yarn weight $=(1.75 \times 1.1944) \times 0.6857$

Calculated weft yarn weight $=1.43325$

Total Calculated weight of fabric $=$

Calculated warp weight + Calculated weft weight

Total Calculated weight of fabric $=2.3161+1.43325=3.74935$

Now, Spandex weight in fabric can be measured by the following formula:

$$
\begin{gathered}
\text { Spandex\% in fabric }=\frac{(\text { weft weight } \times \text { spandex } \% \text { in yarn })}{\text { total calculated weight of fabric }} \\
\text { Equation (17): Spandex } \% \text { in fabric }
\end{gathered}
$$

$$
\begin{aligned}
& \text { Spandex\% in fabric }=\frac{(1.43325 \times 7.526 \%)}{3.74935} \\
& \text { Spandex\% in fabric }=\mathbf{2 . 8 7 6 9 \%} \text { (Answer) }
\end{aligned}
$$

A very little percentage of spandex like $2 \%$ or $3 \%$ is sufficient for improving a fabrics quality like drape and shape retention.

Spandex yarn: Spandex is a brand of Lycra fiber. Spandex is a manmade elastic fiber. It is made from premium quality materials. In yarn, Spandex is not used alone. It is always combined with another fiber natural or manmade. A very little percentage of Spandex like $2 \%$ or $3 \%$ is sufficient for improving a fabrics quality like drape and shape retention. Figure 5 indicates the position of Spandex in yarn.

\section{Properties of Spandex:}

- Melt about at 500-degree F

- It has a good resistance to oxidizing agent

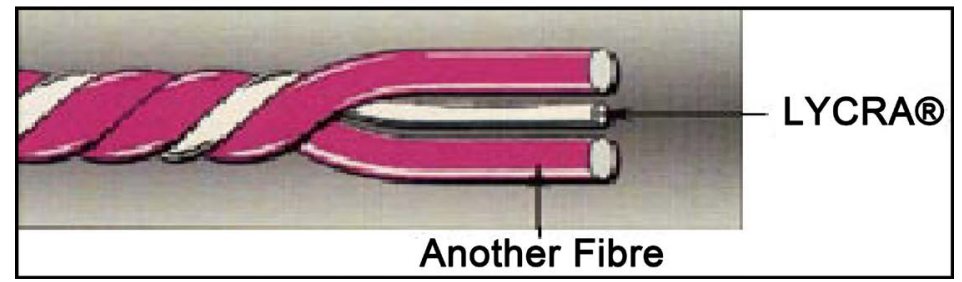

Figure 5. Figure of spandex used in core. 
- It has a poor resistance to bleaches.

- It has a good resistance to sun light.

- It has a good resistance against mildew.

- It has a longer lasting property.

- It acts good in acidic and alkaline condition.

- High stretch, high recovery, low growth.

- Very fine dimensional stability.

A very little percentage of spandex like $2 \%$ or $3 \%$ is sufficient for improving a fabrics quality like drape and shape retention.

\subsection{Identifying the Warp \& Weft Crimp\% in Swatch}

Because of the interlacement in between warp and weft yarns a certain amount of waviness is imparted to the warp and weft yarns of a woven fabric. This waviness is called crimp. Crimp is calculated by straightening or stretching of the wavy yarns. For getting warp crimp\%, we have to find a difference in between the non-stretched yarn length in fabric and stretched yarn length after removing the yarn from fabric and then divide it by non-stretch yarn length in fabric. Then multiply with 100 for getting warp crimp in percentage. Crimp can vary from $2 \%$ up to $30 \%$. Equation (18) and Equation (19) describe warp and weft crimp\%. Figure 6 shown yarn crimp in fabric.

$$
\begin{aligned}
& \text { Warp or Weft crimp\% } \\
& =\left\{\frac{(\text { Stretched yarn length }- \text { nonstretched yarn length })}{\text { nonstretched yarn length }}\right\} \times 100 \\
& \text { Equation (18): warp \& weft Crimp } \%
\end{aligned}
$$

For an example, if the following data are given-

Stretched yarn length after removing the yarn from fabric is $18 \mathrm{~cm}$.

Non-stretched yarn length in fabric is $17 \mathrm{~cm}$.

So,

$$
\begin{gathered}
\text { Physical Warp or Weft crimp } \%=\frac{18 \mathrm{~cm}-17 \mathrm{~cm}}{17 \mathrm{~cm}} \times 100 \\
\text { Equation (19): warp \& weft Crimp\% } \\
\text { Physical Warp or Weft crimp } \%=5.88 \%
\end{gathered}
$$

Effects of yarn crimp in fabric: Due to crimp, fabric is affected by below mentioned things:

Abrasion resistance: Abrasion resistance will be increased, if crimp\% is increased.

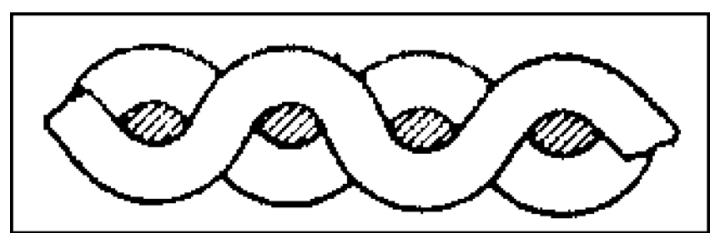

Figure 6. Yarn crimp in fabric. 
Shrinkage: Shrinkage is decreased if crimp\% is increased.

Strength: Strength of fabric like tear and tensile is increased, if crimp\% is increased.

Softness of fabric: Softness of fabric is increased with the increase of crimp\%.

Cost of fabric: Cost of fabric is increased with the increase of crimp\%, as crimp reduces the length of yarn, so more yarns will be required for producing the fabric.

Stiffness of fabric: Stiffness is decreased with the increase of crimp\%.

Absorbency: Absorbency is increased with the increase of crimp\%.

Dimensional stability: Dimensional stability is decreased with the increase of crimp\%.

Dye take up\%: Dye take up percentage is increased with the increase of crimp\%.

\section{Identification of Dye in the Fabric}

\subsection{Identify the Method of Dyeing}

It indicates the method of dyeing, in basis of their manufacturing scheme. It is important to identify the system to be dyed, by analyzing the sample swatches and follow the method. Identifying system is discussed below.

- Fiber dyeing method: Fiber dyeing is the method where, fibers are dyed before blending with other colors to create fancy yarns or fabrics. Fiber dyed yarns are called heather yarns. Heather yarns or fiber dyed yarns are used to create extra effect on fabrics as per buyer's standard.

- Yarn dyeing method: Yarn dyeing is the procedure where yarns are dyed in cone or package form, to make stripe and check effect during weaving or knitting. Yarn dyed fabrics are the fabrics where every yarns are dyed individually.

- Fabric dyeing method: Fabric dyeing is the method where fabric is dyed, after the fabric has been made by weaving, knitting or non-woven process. It is the procedure of decorating white fabric, by means of different colors. It is also a coloration process of fabrics, by the use of different types of dye chemicals.

- Garments dyeing method: Garments dyeing is the method where, dyeing is done after the garments or clothes have been made. During garments dyeing, the penetration or diffusion of dye particles may not be completely passed through the fibers, especially in between the seams, buttons, zippers etc. which confirm this method.

\subsection{Identifying the Swatch is Washed or Unwashed}

Washed fabric: Basically Garment fabrics are washed fabrics because, they are washed after the garments have been made from the finished fabrics. Washed fabrics are generally softer than unwashed fabrics. Washing or garments washing is done after making the garments from the finished fabric. Washed fabric has a 
faded, old, discolored, dull, pale, gray or washed out look or effect in fabric surface compared to unwashed or finished fabric. Washing gives durable softness; elastic and soft handle properties; helps to increase anti pilling effects; helps to control shrinkage or dimensional stability; increases tear resistance; increases color and wash fastness properties; and also improves wearing and easy caring properties.

Unwashed fabric: Basically finished fabrics are the unwashed fabrics because, they are not washed before making the garments. Unwashed fabrics are not as soft as washed fabrics. Unwashed fabric has a bright look where washed fabric has a faded or dull look or effect in fabric surface.

\subsection{Dye Type Identification}

This is the step of identifying dye type whether the dye is reactive, vat, pigment, disperse or others. Basically this test is done in dyeing lab.

Reactive, Vat and Pigment Identifying: It requires to make a solution of 60 gram/liter caustic soda $(\mathrm{NaOH}))$ and 30 gram/liter hydrose $\left(\mathrm{Na}_{2} \mathrm{~S}_{2} \mathrm{O}_{4}\right)$ in hot water. After that if the sample cutting submerged into the solution and the color removed totally, then this is Reactive dye. Again submerge the sample cutting in hydrogen per oxide $\left(\mathrm{H}_{2} \mathrm{O}_{2}\right)$ solution. If the original color does not come back, this is the confirmation of reactive dye. If color comes back again this is Vat dye. During this process Pigment dye will not be changed from the fabric. By this process confirmation about type of dye can be identified in dyeing lab.

Reactive: 60 gm/liter caustic soda $(\mathrm{NaOH})+30 \mathrm{gm} /$ liter hydrose $\left(\mathrm{Na}_{2} \mathrm{~S}_{2} \mathrm{O}_{4}\right)=$ color will be totally removed.

Vat: 60 gm/liter caustic soda $(\mathrm{NaOH})+30 \mathrm{gm} /$ liter hydrose $\left(\mathrm{Na}_{2} \mathrm{~S}_{2} \mathrm{O}_{4}\right)=$ color will start disappearing but not be totally removed. Then dissolve in hydrogen per oxide $\left(\mathrm{H}_{2} \mathrm{O}_{2}\right)$, color will be regained.

Sulpher: 60 gm/liter caustic soda $(\mathrm{NaOH})+30$ gm/liter hydrose $\left(\mathrm{Na}_{2} \mathrm{~S}_{2} \mathrm{O}_{4}\right)=$ color will start disappearing but not totally be removed. Then dissolve in hydrogen per oxide, color will not be regained.

Pigment: 60 gm/liter caustic soda +30 gm/liter hydrose $\left(\mathrm{Na}_{2} \mathrm{~S}_{2} \mathrm{O}_{4}\right)=$ No color change. Categorization of Pigment dye can be done by using an optical microscope, after the fiber specimen is submerged in ethyl salicylate as an optical solvent. If the fibers are more pigmented, pigment elements are noticeable within the fiber. As the fibers are binder-bonded to the pigments in occupied depths, the elements are noticeable on the apparent of the fiber.

Disperse dyes: By boiling a polyester, nylon or acetate sample in ethanol for 2 - 3 minutes, several dye elements may be exposed and moved to un-dyed secondary acetate in the similar solution. Submerge an acrylic sample in fluid paraffin at $160^{\circ} \mathrm{C}$ for $7-8$ minutes in a glycerol solution. Disperse dyes can be slightly stripped and then in some measure move to un-dyed secondary acetate.

\subsection{Identifying the Value of $\mathrm{PH}^{\mathrm{H}}$}

$\mathrm{P}^{\mathrm{H}}$ means potential of Hydrogen. It expresses the negative logarithm of hydrogen 
ion in solution. $\mathrm{P}^{\mathrm{H}}$ scale refers the acidity or alkalinity of a fabric. $\mathrm{P}^{\mathrm{H}}$ value ranges from 1 to 14 . This scale is not a linear scale like meter or inches. It is a logarithmic scale where two adjacent value increases or decreases by a factor. 7 is the neutral point. Below 7 indicates acidity, 1 is the most acidic point and above 7 indicates alkalinity, 14 indicates the most alkaline point.

Indicator is used to show the $\mathrm{pH}$ of a fabric. Indicator changes the color depending on acidic or alkaline medium. If the color changes to red, orange or yellow it indicates $\mathrm{pH}$ value is $1-6$ that is in acidic medium. If the color changes to green, blue or purple, than its value would be $7-14$, that is in alkaline medium.

\subsection{Identify the Type of Finish in Swatch}

By analyzing buyer's swatch, the kind of finishing can be identified:

a) Mechanical finishing: It is given on fabrics mechanically or physically, in dry condition, without using chemicals. Characteristics of these finishing are given below-

Brushing: It is a mechanical process for removing the short, loose, unwanted, protruding and husk fibers from the surface of the fabric by a roller of spiral/ non-spiral revolving brush.

Moireing: Moireing is a mechanical finish that is applied on thermoplastic fibers like acetate, nylon and polyester by wavy/grooved rollers to create an uneven/waved effect on fabrics.

Beetling: It is a mechanical process that is applied on mainly cotton fabrics by beaten with huge timber-wooden blocks to create a hard, flat and lustrous surface in fabrics.

Raising/Napping: It is a mechanical finish by which, upper surface of fabric is raised/pulled/lifted to make the fabric soft, hairy and lighten.

Sanding/Emerizing: It is a mechanical finish by which, fabric is passed through a series of emery-covered rollers to create brushing effect on fabric and to make the fabric soft, flexible.

Sueding: Sand paper is used to rub the fabric and to increase soft hand feel properties.

Glazing: Fabric is treated with glue, starch, paraffin or resin and then rub/ wipe it with heated rollers to raise luster, to control shrinkage and to resist dust, spots etc from fabric.

Calendering: Calendering is a thermo-mechanical process where, at least two heated rollers are used to increase luster, smoothness, to remove crease, pilling problem from fabric.

Sanforizing/Zero-finish: It is a process of finishing without any addition of chemicals to control shrinkage of fabrics in such a way that fabric will not shrink after washing.

b) Chemical finishing: This finish is given on fabrics in wet/damp condition, by using chemicals. Some types of chemical finishing is given below- 
Flame spread finish: This is the ability of flame or fire to spread or to move from one position to another in fabric by a specific period of time [7].

Flame resistance/Fire proof finish: This is the resisting ability of a fabric from burning down by fire/flame or sparks. This type of fabric will resist the fire from burning the fabric [8].

Air permeability finish: Air permeability is the capability of passing air at right angles to the fabric surface under distinct condition.

Water permeability finish: Water permeability is the capability of a fabric to pass water and perspiration in both liquid and vapor form.

Chemical permeability finish: This is the ability of a fabric to permit molecular dispersion of liquid and gaseous chemicals through the fabric and it's desorption into a specific medium.

Water repellent finish: This is the resisting ability of a fabric to wet or absorb, when the fabric will be kept in touch with water.

Waterproof finish: This is the resisting ability of a fabric to the penetration of water vapor and air under much higher hydrostatic pressure than the water repellent fabrics.

Soil release finish: This is the resisting ability of a fabric from making stain in the fabric surface or from making the fabric shabby by the continuous touch of soil, dust, dirt, oil etc.

Crease resistance/Crease recovery/Wrinkle free finish: This is the resisting ability of a fabric from getting creased, folded, and wrinkled in the surface of the fabric.

Resin finish: Resin is applied in order that cross-link in the amorphous region and block free hydroxyl groups, therefore preventing the hydrogen bond formation and improving the crease/wrinkle recovery angle is called resin finish.

Anti-microbial finish: It is a chemical finish, which is given on fabrics to protect the fabric from the harmful effect of insects, microorganism, bacteria, fungus etc.

\section{Yarn Analysis of the Swatch-At Last, Yarn Part Can Be Analyzed by Unplugging the Yarns Form Fabric}

\subsection{Types of Fiber Used in Yarn of Fabric}

- Staple fiber: The normal length of spin able fiber is termed as staple length. Staple fiber is twisted into yarn. It has a limited length varying consistent with the type such as cotton, wool, jute etc. Staple fibers are two types, short (below 0.5 inch) and long staple (above 1.5 inch). The normal staple length of cotton fiber is 0.5 to $2.5 \mathrm{inch}$. Cotton is mainly short staple fiber but most other natural fibers are long staple without silk as silk is a filament fiber (upto $1 \mathrm{~km}$ long). The ratio of length and width of fiber is 1000:1. Staple fibers have brilliant handle properties, satisfactorily covering power, positive comfort rating, reasonable strength, reasonable uniformity etc.

- Filament: It is a fine thread like substance that is found in most body cells. 
The length of a filament is equal to the length of a yarn. Manmade fibers are filament fibers.

\subsection{Identification of Category of Fiber or Yarn Based on Source}

According to resource, yarns or fibers are mainly two types like natural and manmade. Natural fibers are obtained from nature, where human beings create the manmade fibers in an artificial way. Natural or manmade fibers are identified by some tests like burn test, solubility test, stain test and microscopic test etc.

Natural fibers: These fibers are obtained from natural sources. They are of three types like animal or protein fibers, vegetables/plant or cellulose fibers and mineral fibers. Animals or protein fibers are obtained from creature/living beings. Protein fibers are silk, wool from sheep, and hair from animal. Vegetables/ cellulose fibers are obtained from trees. Seed fibers are obtained from cotton, coir; bast fibers are obtained from flax, hemp, jute, ramie etc; and leaf fibers are obtained from abaca, sisal etc. Mineral fibers are obtained from asbestos.

Manmade fibers: They are mainly two types like synthetic fibers and regenerated fibers. Synthetic fibers are produced from synthetic polymer. Polyester, aramid, polyamide/nylon, poly vinyl derivatives, poly olefin, polymethyl are example of synthetic fibers. Regenerated fibers are produced from natural polymer. Cellulose ester, rayon, protein, glass and rubbers are the examples of regenerated fibers.

\subsection{Identify Yarn Ply}

The number of strands those are twisted together to form a yarn is equal to the number of ply. Plied or folded yarns are composed of two or more single yarns those are twisted together. If we un-twist the plied yarn, we will get single yarns. Yarns are plied to increase strength, to increase weave appearance, GSM etc.

Single yarn/spun yarn/one ply yarn: Single yarns of the spun type are composed of many short fibers, require at least a small amount of twist to hold them together, either by "S" or "Z" twist. If we untwist the single spun yarn, we will not get any yarn rather we will get many staple fibers. For an example, 80/1 (read as 80 single) means one yarn of $80 \mathrm{Ne}$.

Plied or folded yarn: Plied yarns are composed by twisting two or more single spun yarns together. Two plied yarn is composed of two single yarns where three plied yarn is composed of three single spun yarns together. In case of producing ply yarns from spun strands, the separate yarns are all twisted in one way and then are twisted in reverse direction to make ply yarns. The number of strands those are twisted together to form the yarn is equal to the number of ply. If we untwist the plied yarns, we will get single yarns. Ply twist is the opposite of yarn twist. For an example, 80/2 (read as 80 double) means two yarns of $80 \mathrm{Ne}$ those are plied or twisted together, resultant count is $40 \mathrm{Ne}$. As the same way, $60 / 3$ (read as 60 triple) means three yarns of $60 \mathrm{Ne}$ those are plied (3 plied) or 
twisted together, resultant count is $20 \mathrm{Ne}$. Figure 7 shows plied yarn [9].

Cabled yarn: It is composed of two or more plied yarns each twisted together. To make cabled yarns from plied yarns, the individual plied yarns are each twisted together in one direction to combine and then are twisted in opposite direction to make cabled yarns. Some number of ply yarns are twisted together to form the cabled yarn. If we untwist the cabled yarns, we will get plied yarns. Cable twist is the opposite of ply twist. Figure 8 shows cabled yarn.

Core spun yarn: Fibers are twisted round a remaining yarn by filament or by staple spun yarn, to make a covering core structure. A yarn in which, a base yarn is completely wrapped/covered with a second yarn. Core spun or poly core yarn is made by twisting staple fibers all around a filament core, which is generally made up with polyester for additional strength. Core spun yarns are composed of two-component structure with core and sheath/cover. Basically, filament yarn is used as core where, staple fibers are used as sheath or covering. Core spun is used to raise the characteristics of fabrics like strength, durability, resiliency, comfort etc.

\subsection{Identification of Yarn Based on Production}

We need to identify the yarn whether it is ring or rotor yarn. There are some dissimilarities between ring and rotor yarns. Basically, ring yarns are finer than rotor yarns. Jeans and denim fabrics are rotor yarns.

- Ring Spun Yarn: Ring yarns are finer yarns. It is spun in ring lay out. They

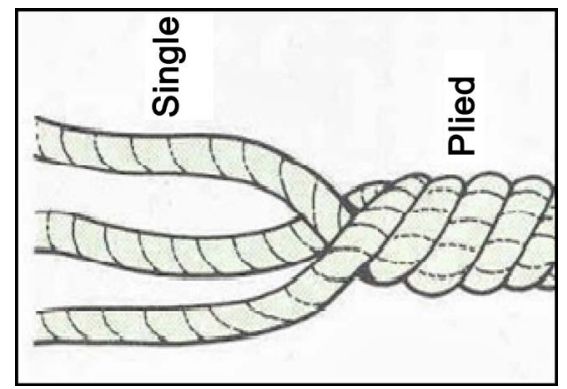

Figure 7. A figure of plied yarn.

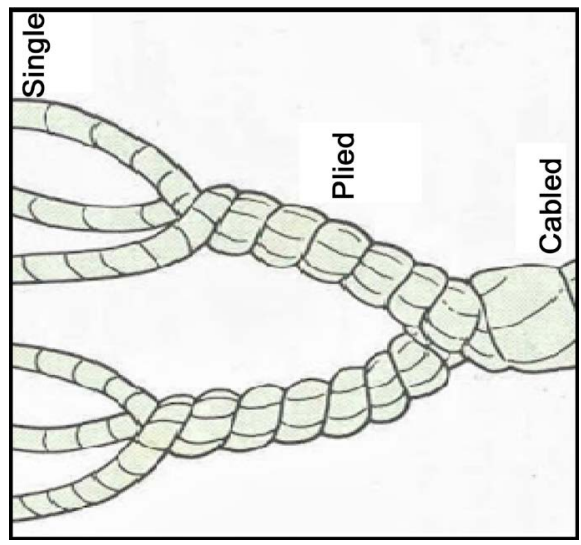

Figure 8. A figure of cabled yarn. 
are " $Z$ " twisted yarns. This is anti-clockwise twist or left-handed twist. These yarns are made up on the ring frame and traveler system. They are smother, softer and stronger than ordinary cotton.

- Rotor Spun Yarn: Rotor yarns are coarser yarns. They are "S" twisted yarns. This is clockwise twist or right-handed twist. Denim industries are much dependent on rotor yarns. Rotor spun yarns are basically made up with short staple fibers.

\subsection{Composition of Yarn/Fiber Identification Test}

This indicates the chemical composition of yarn whether this is natural or manmade yarn like cotton yarn, polyester yarn, nylon yarn, spandex/Spandex yarn or other type of yarn. There are four procedure for fiber composition identification including burning, solubility, dye staining and microscopic tests of the fibers.

Burn test: Burn test is the quickest, easiest and simplest test of fiber identification. A burner is required for burning test. Table 1 shows burn test of fibers.

Solubility test: Taking five to six cut fibers by five to six millimeter each in a test tube of temperature controlled bath with solvent and then observe. Table 2 shows solubility of synthetic fibers inside organic solvents. Table 3 shows solubility of natural fibers inside inorganic solvents.

Microscopic test: For fiber identification, microscope is used to see the longitudinal and cross-sectional view of the most common fibers.

\subsection{Identify Yarn Twist}

Twist means the spiral or coiled nature of the apparatuses of a yarn which is

Table 1. Burn test of fibers.

\begin{tabular}{ccccccc}
\hline $\begin{array}{c}\text { Fiber } \\
\text { Name }\end{array}$ & $\begin{array}{c}\text { Burning } \\
\text { by fire }\end{array}$ & $\begin{array}{c}\text { Burning } \\
\text { continuity }\end{array}$ & Nature of ash & $\begin{array}{c}\text { Melts } \\
\text { near fire }\end{array}$ & $\begin{array}{c}\text { Shrinkage } \\
\text { due to fire }\end{array}$ & Burning smell \\
\hline Cellulose & For sure & For sure & Slide grayish & No & No & Burning like paper \\
Wool & For sure & Gradually & Irregular Black & For sure & For sure & Burning like hair \\
Silk & For sure & Gradually & Soft black & For sure & For sure & Burning like hair \\
Acrylic & For sure & For sure & Hard black & For sure & For sure & Distinctive odor \\
PET & For sure & Gradually & Hard black & For sure & For sure & Burning like wax \\
Nylon & For sure & For sure & Hard gray & For sure & For sure & Characteristic odor \\
\hline
\end{tabular}

Table 2. Solubility of synthetic fibers inside organic solvents.

\begin{tabular}{cccc}
\hline Fiber name & $\begin{array}{c}\text { Di-methyl formamide, } \\
90^{\circ} \mathrm{C}, 8 \text { to } 10 \text { minutes }\end{array}$ & $\begin{array}{c}85 \% \text { formic acid, } \\
20^{\circ} \mathrm{C}, 5 \text { minutes }\end{array}$ & $\begin{array}{c}\text { Glycerol bath, } \\
139^{\circ} \mathrm{C}, 5 \text { minutes }\end{array}$ \\
\hline Acrylic & Solvable & Not Dissolved & Plastic mass formed \\
PET & Not Soluble & Not Dissolved & Soluble \\
Nylon 6 & Soluble & Soluble & Soluble \\
Nylon 66 & Not Soluble & Soluble & Soluble \\
\hline
\end{tabular}


Table 3. Solubility of natural fibers inside inorganic solvents.

\begin{tabular}{cccc}
\hline Fiber name & $\begin{array}{c}59.5 \% \text { sulfuric acid, } \\
20^{\circ} \mathrm{C}, 20 \text { minutes }\end{array}$ & $\begin{array}{c}70 \% \text { sulfuric acid, } \\
38^{\circ} \mathrm{C}, 20 \text { minutes }\end{array}$ & $\begin{array}{c}5 \% \text { sodium hypochlorite, } \\
20^{\circ} \mathrm{C}, 20 \text { minutes }\end{array}$ \\
\hline Cotton & Not Soluble & Soluble & Not Soluble \\
Wool & Not Soluble & Not Soluble & Soluble \\
Silk & Soluble & Soluble & Soluble \\
Rayon & Soluble & Soluble & Not Soluble \\
\hline
\end{tabular}

usually the result of relative rotation of the two ends. Twist is generally expressed as the number of turns per unit length of yarn. This part of analysis identifies the yarns, to confirm whether it is twisted or not twisted.

Twist less Yarn: Twist less yarns are made up with staple fibers (either short of long staple), here the joining of fibers is done with adhesive. Figure 9 shows twist less yarn.

Twisted Yarn: To manufacture the yarns of staple fibers, twist is injected to the fibers, to hold the fibers together and to impart the desired spiral characteristics to the twisted yarns. Without twist, the strand of fibers will not be strong. Twisted yarns may be a single yarn or a double yarn. Short fibers are twisted to make a single yarn, on the other hand, single yarns are twisted to make plied yarns. Figure 10 shows twisted single spun yarn.

a) Twisted single spun yarn: Single yarns are made up with many short fibers, needs at least a small amount of twist to hold them together, either by " $\mathrm{S}$ " or "Z" twist.

b) Twisted Ply yarn: Plied yarns are made up with twisting two or more single spun yarns. Two plied yarn is composed of twisting two single yarns, where three plied yarn is composed of twisting three single spun yarns. Figure 11 shows twisted ply yarn combining single yarn.

\subsection{Identify Yarn Twist Direction}

The spiral character of yarn that is basically the consequence of relative rotation of head and tail of a same yarn, that is called yarn twist. It is an important factor of yarn, which enhances the strength. It will be identified in both warp and weft direction. There are two types of twist in yarns those are "S" and " $Z$ " twist. Twist is the number of turns about its axis per unit of length of a yarn or other textile strand. One end is fixed and other end is turned, this the principle of yarn twists. Figure 12 shows " $S$ " twist and "Z" twist in yarn.

\subsection{Twist Measurement}

It is an important test of yarns. Due to the difference of twist across the yarn length, twist measurement should be done very carefully.

Straightened Fiber Method: It includes calculating the number of turns needed to untwist the yarns till the external fibers seem to be straight and parallel to yarn axis. 


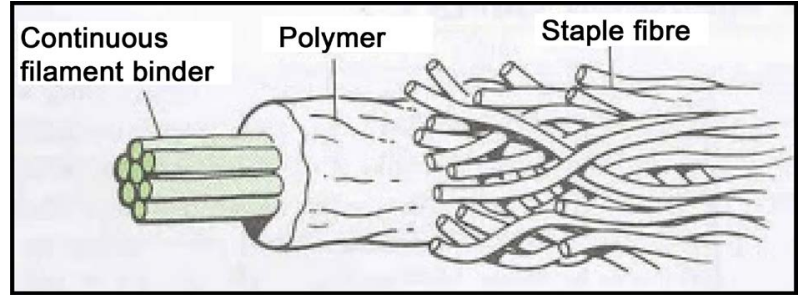

Figure 9. Twist less yarn.

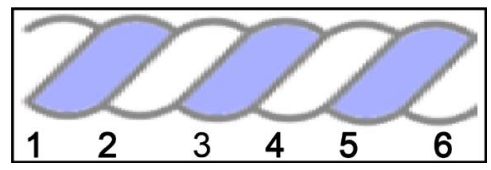

Figure 10. Twisted single spun yarn.

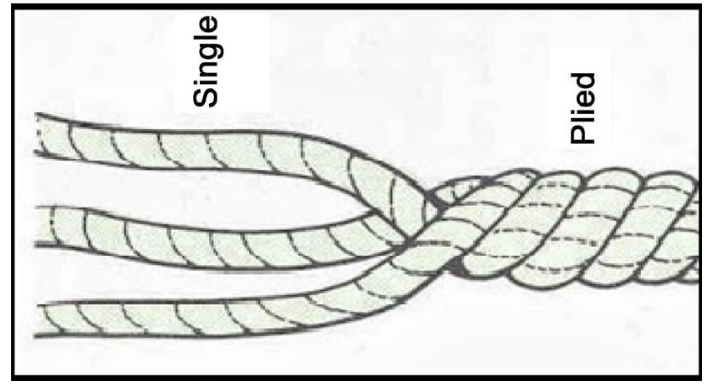

Figure 11. Twisted ply yarn (combining single yarns).

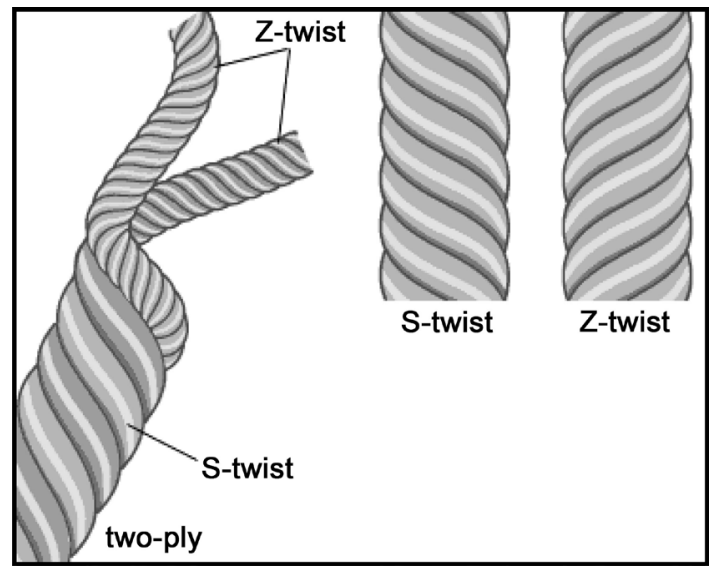

$\mathrm{S}$ Twist = It is a clockwise twist or right handed twist, mainly Rotor yarns are "S" twisted yarn. These yarns can create good twill prominence in RHT twill or Z twill weave. Z Twist = It is an anti-clock wise twist or a left handed twist, mainly Ring yarns are "Z" twisted yarn. These yarns can create good twill prominence in LHT twill or S twill weave.

Figure 12. S Twist and Z Twist in yarn.

Untwist or Re-Twist Method: To find out the twist level of a $\mathrm{Z}$ twisted yarn, the yarn initially untwisted, by a twist tester, to record the number of turns. Due to untwisting, the length of yarns will be increased from its original length. By continuing this, all twist will be removed from the yarn, subsequently it will be twisted to $S$ direction again. For being twisted, again its length will be decreased (twist contraction) from its twist less position. Total number of turns will be 
equal to double, to get the original length, from $\mathrm{Z}$ twist, all the way through untwist, up to $S$ twist.

\subsection{Identifying the Twist Angle in Yarn}

The twist angle of yarns can be calculated. The yarn twist angle is an angle in between a tangent to the spiral/coil that is created by a fiber on the yarn surface besides the axis of yarn. Figure 13 shows the measurement of yarn twist angle. Equation (20) describes twist angle.

$$
\text { Twist Angle, } \operatorname{Tan} \theta=\frac{d \Pi}{L}
$$

Equation (20): Measurement of Yarn Twist Angle

Twist angle is measured by $\tan \theta$.

Yarn diameter is measured by $d$.

$L$ is the height (pitch) of one turn of twist.

\subsection{Calculate TPI of Yarn}

Number of twist per inch in plied yarns can be determined by counting the number of bumps in one inch and divide by the number of single yarns. Number of twist is measured both by counting the number of turns about its axis in oneinch length or by formula. Figure 14 shows twist per inch in yarn. Equation (21) describes the formula of TPI measurement.

Formula: In industries, twist per inch is calculated by the following methods-

$$
\text { TPI }=\text { Twist factor }(K) \times \sqrt{\text { count }}
$$

Equation (21): Yarn TPI measurement

Twist factor is an experimental parameter that is determined by experiment and practice about the extreme strength of yarn that is got for a certain value of $\mathrm{K}$.

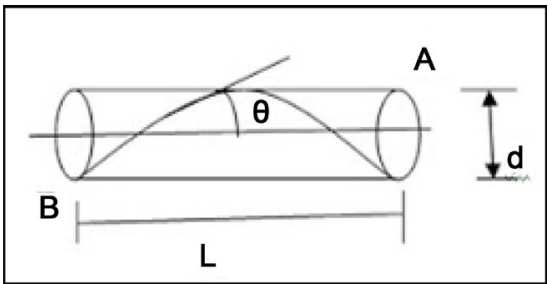

Figure 13. Measurement of yarn twist angle.

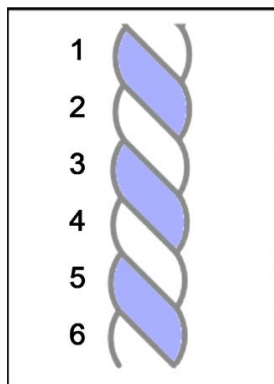

Figure 14. Twist per inch (TPI) in yarn. 


\subsection{Identifying the Quality of Yarn}

The quality of yarn specifies whether it is OE, Card, Comb or Compact.

$\mathrm{OE}$ Yarns = Open End yarns are very coarser yarns. The count $(\mathrm{Ne})$ of $\mathrm{OE}$ yarn is very low. Most of the OE yarn count is below 20's in case of non-denim fabrics. In case of OE yarns, Drawn Slivers are used in Rotor to make OE Yarns. Where in Ring yarns drawn slivers are used in Simplex, to make Roving, then ring frame to yarns. Coarser and thick fabrics are manufactured by $\mathrm{OE}$ rotor yarns. Denim industries are totally dependent on OE Rotor yarns.

Carded Yarns $=$ Carded yarns are improved yarns than OE yarns. Carding is the process of removing impurities, dust and darts, which are not removed in the previous cleaning process. Parallelizing and stretching of the fiber is done here that helps to remove neps in the further process. Short fibers are also removed in this step.

Combed Yarns $=$ Combed yarns are better yarns than carded yarns. Combing is the procedure of uncurling and fibers parallelizing by eliminating the impurities and short fibers by a comb aided with brushes and rollers. It is done to improve the excellence of sliver that comes out of the card. This procedure reduces short fibers, it attains good parallelization of fibers, it straightens curls, and it eliminates leftover impurities like dust, dirt etc and neps. Combed yarns are less hairy than carded yarns. Actually, combed yarns are most often used to make the yarns of nearly $20 \mathrm{Ne}$ to up approximately 40 to $60 \mathrm{Ne}$.

Compact Yarns $=$ Compact is the improved ring spun yarn, which has less hairiness, less imperfections, improved evenness, more uniformity and more strength. Compact spinning system avoids the formation of spinning triangle that minimizes protruding and hairy fibers. Higher count or finer yarns can be produced by compact spinning method.

\subsection{Identifying Slub Parameters}

An abruptly thick place and thin place of a yarn is called slub yarn. Thick place is a yarn fault, where the diameter is greater than the adjoining segments and extending for $6 \mathrm{~mm}$. A yarn segment, where the diameter is $25 \%$ lesser than the average diameter of a yarn is called thin place. A short thick nub in yarn that is either an imperfection or is purposely used for a desired effect in fabric is called a slub yarn. A ground slub yarn is formed of a single structure that has two parts, one is slub part and another one is base yarn part. A slub yarn has three major parameters like slub length, slub diameter and slub distance [10]. Figure 15 shows slub specification in yarn.

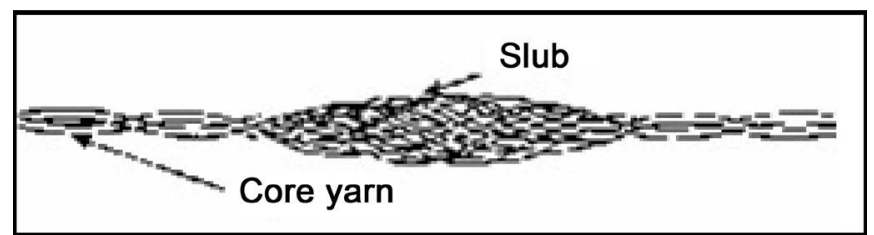

Figure 15. Slub details in yarn. 
Slub Length: Slub length represents the length of thickened region in yarns. Slub length is the length from starting point of a thickened slub to the ending point of a thickened slub in yarn. Slub length is measured at different thickened places of yarns and then their average value is taken as a value of slub length. It is mainly measured by uster tester machine.

Slub Diameter: Slub diameter is the diameter of the thickened region of yarn. Slub thickness represents the mass ratio in between the slub part and the base part. Slub diameter is measured at different thickened places of yarns and then their average value is taken as a value of slub diameter. It is mainly measured by uster tester machine.

Slub distance: Slub distance represents the length of base yarn in between two successive slubs. The distance in between two slubs is called slub distance. The distance of one slub from another slub is called slub distance. Slub distance is measured in different places of yarns and then their average value is taken as a distance of slub. Slub distance is mainly measured by uster tester machine.

\subsection{Measurement of Yarn's Fineness}

Fineness of yarns expresses linear density of yarns. A number that indicates the mass per unit length or the length per unit mass of yarn. Fineness of fiber determines the fineness of yarn that must be measured in relation to its length and width. Yarns fineness can be measured by yarn fineness tester machine.

\subsection{Yarn Diameter Calculation}

Yarn diameter is the thickness or thinness of yarns. It is dependent on the amount of fibers remains in the cross section, fiber coarseness or fineness, the density of yarn, twist of yarn with the internal or external yarn structure. Yarn diameter is strongly affected by the surface fiber arrangement, density, surface faults etc. Yarn's roundness or shape depends on spinning procedure (ring or rotor) and yarn type. If the yarns are finer (Ne increases), the diameter value decreases, the density value increases as twist per inch increases. Alternatively, if the yarns are coarser (Ne decreases), the diameter value increases. Equation (22) expresses yarn diameter.

$$
\begin{aligned}
& \text { Yarn diameter }(\text { inch })=\frac{1}{(28 \times \sqrt{\text { count Ne}})} \\
& \text { Equation (22): Yarn diameter calculation }
\end{aligned}
$$

\subsection{Yarn Density/Compactness Measurement}

Actually, yarn density is the measurement of yarn's compactness. It is related with yarn twist. If twist is increased, yarn density is increased and if twist is decreased, yarn density is also decreased. Ring spinning yarns have higher twist, higher density where rotor spinning yarns have lower twist, lower density. Ring spinning yarns are finer than rotor spinning yarns. Rotor spinning yarns are coarser with low twist having low density. Compact yarns have higher twist 
compared to combed yarns where OE rotor yarns have least density. Yarn density is measured by $D$. Equation (23) expresses yarn density or compactness measurement.

$$
D\left(\mathrm{gm} / \mathrm{cm}^{3}\right)=\frac{4 \mathrm{~m}}{\left(d^{2} \times \Pi \times l\right)}
$$

Equation (23): Yarn density/compactness Measurement

where, $m=$ mass of yarns in gram. (by balance)

$d=$ yarn diameter in centimeter scale.

$I=$ length of yarns in centimeter.

$\Pi=3.1416$.

\subsection{Yarns Shape/Roundness Measurement}

Shape/roundness of yarns affects the appearance and look of fabric. It is a measurement of the yarns average roundness on the whole yarn length (centimeter). This value corresponds to the percentage of the short to long chief axis of an ellipse ( 1 cycle). If the shape value is nearly to 1 , the yarn will have a circular cross section. Roundness or Shape $=\frac{m}{n}$. Figure 16 shows yarn roundness measurement.

\subsection{Measurement of Yarn's Evenness}

Yarn evenness is the measurement of level of variation in yarn linear density or mass per unit length of yarn. It also refers to the variation in yarn count with its length. Filament yarns have almost no variation in linear density so evenness is fine. Mainly, evenness is measured for the spun yarns of staple fibers. Yarns of poor evenness will have thick and thin places along with yarns length, where an even yarn will have little variation in mass or thickness along length. Twist has a tendency to build up the thin places in yarn that creates irregularity in yarn linear density and creates variations in yarn diameter or thickness. Large variations in yarn linear density due to high twist, there may have some thin spots in yarn those are called weak spots. A perfectly even spun yarn has fibers of uniform thickness and the yarn has same number of fibers in all cross sections along with its length.

\subsection{Measurement of Yarn's Hairiness}

Hairiness refers to the presence of small hairy fibers, projecting or protruding

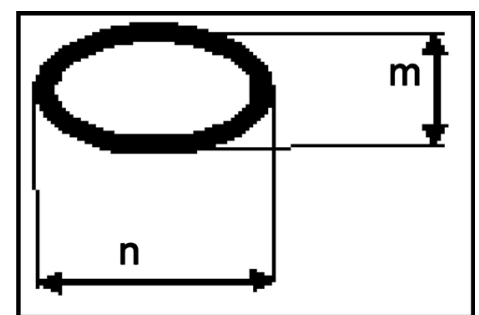

Figure 16. Roundness measurement of yarn. 
fibers on the surface of the textile yarns. In a staple spun single yarn, multiple fibers will tend to protrude outside the body of the yarns, even though proper twisting is applied. Hairiness refers to the term Hairiness Index (HI) that represents the total length of hairs in $\mathrm{cm}$, measured over the yarn length of $1 \mathrm{~cm}$. Other way of hairiness representation is, counting the number of hairy fibers for a given length of yarn. It varies from $3 \mathrm{~mm}$ to $10 \mathrm{~mm}$. "Hair severity" is a test parameter that refers to the harshness, strictness, brutality of longer yarns etc. Hairiness is measured in two different ways, one is uster Hairiness Index and another one is Zweigle Hairiness Index. In Uster, Hairiness Index H corresponds to the total length of protruding fibers within the measurement field of $1 \mathrm{~cm}$ length of yarn. In Zweigle, Hairiness measurement gives the number of protruding fibers more than $3 \mathrm{~mm}$ in length, in 1 meter of the yarn.

\subsection{RKM Test of Yarn}

RKM refers resistance per kilometer, which is a vital parameter of a yarn that can be measured by RKM tester (uster) machine. Higher RKM value determines the better quality of yarn. Average RKM value of cotton yarn ranges from 18 - 22 [11].

\section{Conclusion}

The findings of this project are that, swatch analysis covers a huge area those are related to spinning, weaving and wet processing. Good analytical work can bring about a good result by developing quality full product. If a product cannot be analyzed properly, it will not be possible to know what actually it contains inside it. Fabric part, dye part and yarn part analysis is the systematical way to analyze a fabric which will ultimately go for an improvement of development of any textile products. Good lab facilities are required to do a better analysis of a textile cloth. Accurate idea of a fabric can be achieved by analysis. For finding out costing a fabric, this analysis is also very much important. A good team work is mandatory to do a better investigation on a fabric.

\section{References}

[1] Behera, B.K. (2004) Performance of Error Back Propagation Vis-a-Vis Radial Basis Function Neural Network: Part I: Prediction of Properties for Design Engineering of Woven Suiting Fabrics. Journal of the Textile Institute.

[2] Haque, Md.M. (2010) Effect of Weft Parameters on Weaving Performance and Fabric Properties. Daffodil International University Journal of Science and Technology.

[3] Mitra, A., Majumdar, A., Majumdar, P.K. and Bannerjee, D. (2013) Predicting Thermal Resistance of Cotton Fabrics by Artificial Neural Network Model. Experiment al Thermal and Fluid Science.

[4] Majumdar, A. (2010) Engineering of Cotton Fabrics for Maximizing in Vitro Ultraviolet Radiation Protection: Engineering of Cotton Fabrics for UV Protection. Photodermatology Photoimmunology \& Photomedicine.

[5] Ko, J. and Park, P. (2010) An Experimental Study on the Fire Risk Assessment and 
Calculation Breakthrough Time through Permeation Test of Chemical Protective Clothing. Journal of Korean Institute of Fire Science and Engineering, 24, 21-30.

[6] Wilson, J. (2014) Woven Structures and Their Characteristics. Woven Textiles, Process Control in Ring Spinning, Process Management in Spinning.

[7] Jang, B.N. and Choi, J. (2009) Research Trend of Flame Retardant and Flame Retardant Resin. Polymer Science and Technology, 20, 8-15.

[8] Lee, S.H. (2013) Fabrication and Characteristics of Flame Retardant Fabric Developed by Using Component Filament. Textile Coloration and Finishing, 25, 110-117. https://doi.org/10.5764/TCF.2013.25.2.110

[9] Belal, S.A. (2009) Understanding Textiles for a Merchandiser. BMN3 Foundation, Dhaka, 21-25.

[10] Musa, K. and Ayse, O. (2006) Relationships between Yarn Diameter/Diameter Variation and Strength. Fibres and Textiles in Eastern Europe, 14, 84-87.

[11] Penava, Z. and Orešković, V. (1997) Analysis of the Coincidence between Thin Places and Breaking Points in a Yarn. Journal of the Textile Institute, 88, 21-32. https://doi.org/10.1080/00405009708658526 